\title{
Profile of tobacco users identified in primary care practice and predictors of readiness to quit: a cross-sectional survey
}

\author{
Sophia Papadakis PhD, Heather E. Tulloch PhD, Marie Gharib BSc, Andrew L. Pipe MD
}

Abstract

Background: The aim of this study was to document the prevalence of tobacco use and describe the characteristics of tobacco users identified in primary care practices.

Methods: We conducted a cross-sectional survey in 49 primary care practices in the province of Ontario. Consecutive patients were screened for smoking status at the time of their clinic appointment. Patients reporting current tobacco use completed a survey, which documented sociodemographic and smoking-related characteristics. Multilevel modelling was used to examine predictors of readiness to quit smoking and the presence of anxiety and/or depression.

Results: A total of 56592 patients were screened, and 5245 tobacco users participated in the survey. Prevalence of tobacco use was $18.2 \%$ and varied significantly across practices (range $12.4 \%-36.1 \%$ ). Of the respondents, $46.3 \%$ reported current anxiety and/or depression, and $61.3 \%$ reported smoking within the first 30 minutes of waking. A total of $41.1 \%$ of respondents reported they were ready to quit smoking in the next 6 months, and $30.1 \%$ reported readiness to quit in the next 30 days. Readiness to quit was positively associated with higher self-efficacy, male sex, presence of chronic obstructive pulmonary disease and more years of tobacco use. The presence of anxiety and/or depression was associated with lower cessation self-efficacy and time to first cigarette within 30 minutes of waking, but did not predict readiness to quit.

Interpretation: Tobacco users identified in primary care practices reported high rates of nicotine dependence and anxiety and/or depression, but also high rates of readiness to quit. Study findings support the need to tailor interventions to address the needs of tobacco users identified in primary care settings.

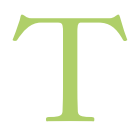

obacco use is the leading cause of preventable death globally. ${ }^{1}$ Primary care practice is an important setting for intervening with smokers and assisting with cessation. ${ }^{1,2}$ In North America, an estimated $70 \%-80 \%$ of tobacco users will visit a primary care provider at least once annually; similar rates are reported internationally. ${ }^{3-6}$ These visits represent an opportunity to identify the smoking status of patients, offer advice to quit and brief motivational interventions, and support cessation..$^{7-9}$

Increasing the rates of tobacco treatment delivery in clinical settings has been identified as an important target for tobacco control and the reduction of health care costs. ${ }^{1,6}$ Although there have been important improvements in this area, there remains a "practice gap" in the rates at which tobacco treatments are being delivered. ${ }^{7-10}$ Many clinicians identify patient-level barriers to treatment delivery, including low patient motivation to quit, the clinical complexity of their patients and a perceived lack of effectiveness in assisting patients with cessation. ${ }^{11,12}$ A more in-depth understanding of the characteristics of tobacco users identified in the primary care setting is critical for informing future intervention design. The purpose of this investigation was to examine the prevalence of tobacco use, the demographic and smokingrelated characteristics of smokers identified in a sample of primary care practices, and predictors of readiness to quit.

Competing interests: Sophia Papadakis and Andrew Pipe contributed to the development of the Ottawa Model for Smoking Cessation. Andrew Pipe reports personal fees from Pfizer, Johnson \& Johnson and Amgen. No other competing interests were declared.

This article has been peer reviewed.

Correspondence to: Sophia Papadakis, SPapadakis@ottawaheart.ca CMAJ Open 2016. DOI:10.9778/cmajo.20150055 


\section{Methods}

\section{Design and setting}

Data collection activities occurred in a sample of 49 primary care practices in the province of Ontario. An invitation to participate in the study was sent to all family health teams $(n=90)$ from 6 health regions in Ontario (Champlain Local Health Integration Network [LHIN], South East LHIN, Central East LHIN, Waterloo Wellington LHIN, Mississauga Halton LHIN and Erie St. Clair LHIN). A telephone call was also placed by a member of the project team to confirm receipt and answer any questions about study participation. From each participating primary care practice, a crosssectional sample of patients who used tobacco completed the study survey.

\section{Sources of data}

In each primary care practice, consecutive patients scheduled for an annual examination or nonurgent appointment were screened for eligibility upon check-in to the clinic. A research assistant was located in primary care practice waiting rooms and was responsible for screening all patients for eligibility and for all data collection activities. Patients were eligible to participate if they met the following criteria: (1) a current smoker ( $\geq 1$ cigarette per day in past 7 days); (2) 18 years of age or older; (3) had a scheduled appointment with a clinic physician or nurse practitioner; and (4) were able to read and write in English or French. All eligible patients were asked to complete a brief survey. Participants completed the survey independently and were identified only by study identification number. Participants were encouraged to complete the survey before leaving the clinic; however, if time was a barrier, participants were asked to complete the survey at home and return it by mail. A stamped envelope with the return address was provided to participants who chose this option. Data collection occurred in each primary care practice over a 1-month period to gather a representative sample. If a minimum sample of 50 eligible patients was not recruited, data collection was extended for up to 4 weeks. The minimum sampling period of 4 weeks was selected to provide a sufficient time frame to be representative of typical clinical practice. The minimum sample of 50 patients was used to ensure smaller primary care practices had a sufficient sample for which comparisons could be made.

\section{Survey instrument}

The survey instrument is presented in Appendix 1, available at www.cmajopen.ca/content/4/1/E41/suppl/DC1. The survey was pilot tested in 2 clinics and uses previously validated survey items. The survey assessed patient demographic characteristics (i.e., age, sex and years of formal education), selfreported presence of comorbidities ("Do you have any of the following conditions?: heart disease, stroke, heart failure; cancer; chronic obstructive pulmonary disease; diabetes; anxiety or depression"). Nicotine dependence was assessed using the Heaviness of Smoking Index, which is a well-validated self-report measure. The Heaviness of Smoking Index includes
2 items: time to first cigarette in the morning ("How soon after waking in the morning do you smoke your first cigarette?") and number of cigarettes smoked per day ("On average how many cigarettes do you smoke per day?"). ${ }^{13}$ The total number of years the patient had been smoking was documented. Participants' stage of readiness to quit smoking was assessed using an adaptation of the Prochaska and DiClemente's Transtheoretical Model, which classifies tobacco users in 1 of 3 stages: precontemplators (smokers who are not thinking about quitting), contemplators (smokers who are thinking of quitting in the next 6 months) and preparation (smokers who are thinking about quitting in the next 30 days). ${ }^{14}$ Cessation self-efficacy (confidence in one's ability to abstain) was assessed using a previously validated single item: "On a scale of 0 to 10 how confident are you that you would be able to quit smoking at this time? "15-17 This item has been shown to be a robust predictor of long-term smoking abstinence. $^{18}$

\section{Statistical analysis}

Descriptive statistics were used to summarize tobacco-use prevalence and the characteristics of tobacco users. Participants' characteristics were compared using $\chi^{2}$ tests or 2 -sample $t$ tests. Multilevel regression techniques were used to examine those patient characteristics associated with the presence of anxiety or depression (yes/no) as well as readiness to quit in the next 30 days, controlling for clinic and providerlevel variance due to the clustered nature of the data. Odds ratios (ORs) and $95 \%$ confidence intervals (CIs) were used to summarize the effects of each explanatory variable in a final model. Self-efficacy was dichotomized based on scale $(0=$ under 7; $1=7-10)$. Missing data were not replaced and were less than $1 \%$ for any single variable. MLwiN version 2.02 was used to conduct multilevel modelling.

\section{Results}

Data collection occurred between September 2009 and December 2013. A total of 49 primary care practices agreed to participate and contributed data to the present analysis (54.4\% response rate). Primary care practices represented $30 \%$ of all family health teams in the province of Ontario. Participating practices included a representative mix of urban and rural clinics and practices sizes, as well as small and large clinics. Participating practices were more likely to be located in rural or suburban areas than nonparticipating practices. No other differences in clinic characteristics were documented.

A total of 56592 patients were screened, 9215 eligible participants were identified and 5245 tobacco users participated in the survey (56.9\% participation). The primary reason provided for nonparticipation was lack of time. A total of 489 patients left the clinic without seeing the research assistant to complete the survey. Additionally, among participants who chose to return the survey by mail, 528 did not return their survey after 2 reminder calls. The recruitment flow diagram is presented in Figure 1. 


\section{Prevalence of tobacco use}

The prevalence of tobacco use in the sample was $18.2 \%$ (SD $4.9 \%)$. Rates of tobacco use varied significantly among primary care practices sampled, ranging from $12.4 \%$ to $36.1 \%$. The highest rates of smoking were documented in urban centres (downtown core) and rural areas.

\section{Characteristics of tobacco users}

Table 1 displays the profile of tobacco users overall and by readiness to quit categories. The mean age of the study sample was 47.4 (95\% CI $47.0-47.8)$ years. A total of $26.8 \%$ of participants reported the presence of 1 or more smokingrelated illnesses. A large proportion of patients self-reported the presence of current anxiety and/or depression (46.3\%). Table 2 provides a comparison of the characteristics of tobacco users with and without anxiety or depression.

Participants were relatively heavy smokers, consuming a mean of 16.6 (95\% CI 16.3-16.9) cigarettes per day for a mean of 27.5 (95\% CI 27.1-27.9) years. Of respondents, $61.3 \%$ reported smoking within 30 minutes of waking, a proxy for significant nicotine addiction. A total of $30.1 \%$ of participants reported they were ready to quit in the next 30 days. An additional $41.1 \%$ of participants reported that they were ready to quit smoking in the next 6 months (Table 1).

\section{Multilevel modelling}

Readiness to quit in the next 30 days was associated with significantly greater cessation self-efficacy, male sex, having smoked between 5 and 15 years, and the presence of chronic obstructive pulmonary disease (COPD) (Table 3). There was no association between readiness to quit smoking and reported anxiety and/or depression.

Multilevel modelling found tobacco users with selfreported anxiety or depression were significantly more likely to be female, to be over the age of 25 , to report the presence of COPD, to commence smoking within 30 minutes of waking in the morning and to report lower cessation self-efficacy (Table 4).

\section{Interpretation}

Increasing the delivery of cessation treatment within primary care settings is an identified target for many provincial tobacco control strategies in Canada and is one of the goals of the World Health Organization's MPOWER initiative. ${ }^{1,2,19}$ (The acronym MPOWER is derived from "Monitor tobacco use and prevention policies; Protect people from tobacco smoke; Offer help to quit tobacco use; Warn about the dangers of tobacco; Enforce bans on tobacco advertising, promo-

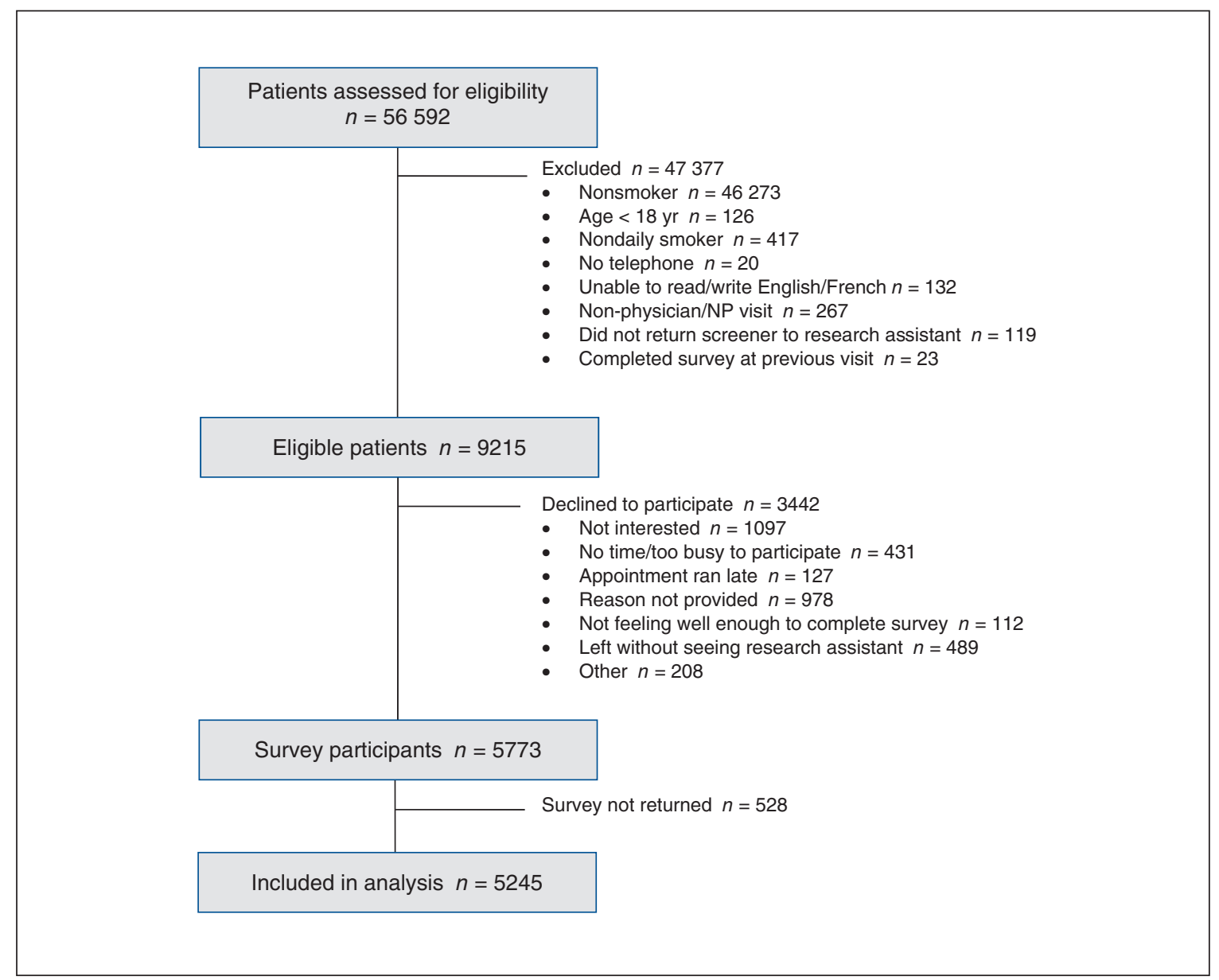

Figure 1: Recruitment flow diagram. Note: NP = nurse practitioner. 


\section{OPEN}

Research

tion and sponsorship; Raise taxes on tobacco.") In our study, $18.2 \%$ of all patients screened reported current use of tobacco products. Tobacco users identified in primary care practices reported high rates of nicotine dependence and anxiety and/or depression, but also high rates of readiness to quit. Readiness to quit was positively associated with higher self-efficacy, male sex, presence of COPD and more years of tobacco use.

The prevalence of tobacco use reported in our study is slightly higher than current rates of smoking in Canada
$(17.3 \%) .{ }^{4}$ There was large variation in prevalence rates of tobacco use across primary care practices, with higher rates of tobacco use documented in the downtown core of urban centres and in rural areas, consistent with previous reports. ${ }^{20}$ The distribution of tobacco users across age categories was similar to the distribution reported in available provincial and national reports of population-based tobacco use. ${ }^{4}$ The only exception was that the proportion of younger (18$39 \mathrm{yr}$ ) male tobacco users identified in primary care practices

Table 1: Profile of tobacco users identified in primary care practices, by readiness to quit*

\begin{tabular}{|c|c|c|c|c|c|}
\hline \multirow[b]{2}{*}{ Characteristic } & \multirow[b]{2}{*}{$\begin{array}{c}\text { Total } \\
n=5245\end{array}$} & \multicolumn{3}{|c|}{ Readiness to quit, \%† } & \multirow[b]{2}{*}{$p$ value $\ddagger$} \\
\hline & & $\begin{array}{l}\text { Ready in next } 30 \mathrm{~d} \\
\quad n=1547\end{array}$ & $\begin{array}{l}\text { Ready in next } 6 \text { mo } \\
\qquad n=2115\end{array}$ & $\begin{array}{l}\text { Not ready } \\
n=1479\end{array}$ & \\
\hline Age, mean $(95 \% \mathrm{Cl})$, yr & $47.4(47.0-47.8)$ & $46.1(45.4-46.8)$ & $46.5(45.9-47.1)$ & $49.8(49.0-50.6)$ & $<0.001$ \\
\hline \multicolumn{6}{|l|}{ Sex } \\
\hline Male & 42.2 & 44.6 & 40.6 & 42.1 & \multirow[t]{2}{*}{0.07} \\
\hline Female & 57.8 & 55.4 & 59.4 & 57.9 & \\
\hline \multicolumn{6}{|l|}{ Education level } \\
\hline$<$ High school & 22.3 & 21.2 & 20.4 & 26.2 & \multirow[t]{4}{*}{$<0.001$} \\
\hline High school & 33.2 & 31.0 & 33.2 & 35.4 & \\
\hline Some postsecondary & 23.9 & 25.1 & 25.0 & 21.1 & \\
\hline University degree & 20.6 & 22.7 & 21.5 & 17.3 & \\
\hline Smoking-related illness & 26.8 & 27.3 & 25.9 & 27.2 & 0.7 \\
\hline $\begin{array}{l}\text { Heart disease, heart attack, heart } \\
\text { failure, stroke }\end{array}$ & 10.9 & 10.2 & 10.3 & 12.3 & 0.2 \\
\hline Diabetes & 13.1 & 13.0 & 13.0 & 13.3 & 0.9 \\
\hline Cancer & 3.9 & 3.9 & 3.4 & 4.5 & 0.2 \\
\hline COPD & 8.7 & 11.0 & 8.2 & 7.1 & $<0.001$ \\
\hline Anxiety/depression, self-reported§ & 46.3 & 45.9 & 47.0 & 45.7 & 0.7 \\
\hline Cigarettes per day, mean $(95 \% \mathrm{Cl})$ & $16.6(16.3-16.9)$ & $15.7(15.2-16.3)$ & $16.3(15.9-16.7)$ & $18.0(17.4-18.5)$ & $<0.001$ \\
\hline No. of years smoking, mean $(95 \% \mathrm{Cl})$ & $27.5(27.1-27.9)$ & $25.4(24.7-26.2)$ & $26.7(26.1-27.3)$ & 30.7 (29.9-31.5) & $<0.001$ \\
\hline \multicolumn{6}{|c|}{ Time (min) to first cigarette in the morningl } \\
\hline$>60$ & 19.5 & 21.5 & 18.9 & 18.2 & \multirow[t]{4}{*}{$<0.001$} \\
\hline $31-60$ & 19.2 & 18.9 & 20.6 & 17.3 & \\
\hline $6-30$ & 35.0 & 33.5 & 37.1 & 33.6 & \\
\hline$\leq 5$ & 26.3 & 26.1 & 23.4 & 30.8 & \\
\hline \multicolumn{6}{|l|}{ Readiness to quit* } \\
\hline Ready in next $30 \mathrm{~d}$ & 30.1 & - & - & - & - \\
\hline Ready in next 6 mo & 41.1 & - & - & - & - \\
\hline Not ready & 28.8 & - & - & - & - \\
\hline $\begin{array}{l}\text { Cessation self-efficacy, mean score } \\
(95 \% \mathrm{Cl})^{\star \star}\end{array}$ & $5.1(5.0-5.2)$ & $6.6(6.5-6.7)$ & $5.4(5.3-5.5)$ & $2.8(2.6-2.9)$ & $<0.001$ \\
\hline \multicolumn{6}{|c|}{ 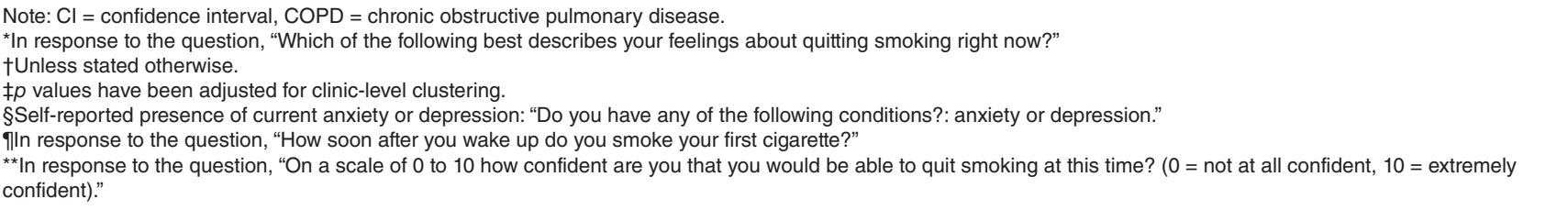 } \\
\hline
\end{tabular}


surveyed was lower than the reported prevalence of men who smoke in Canada. This is consistent with previous reports that have found that a third of men aged 20-39 years in Canada have not seen a general practitioner in the previous 12 months. ${ }^{3}$ Study participants also reported higher levels of university education than the known population of smokers in Canada. ${ }^{21}$

Most participants reported high rates of nicotine dependence, with $61.3 \%$ of tobacco users reporting smoking within the first 30 minutes of waking compared with $42 \%$ identified in population surveys in Ontario. ${ }^{4}$ This observation is important, given that individuals with higher levels of nicotine dependence report fewer quit attempts and less success with quitting. ${ }^{22-25} \mathrm{We}$ found that a large proportion of tobacco users reported the presence of a smokingrelated illness. Importantly, $46.3 \%$ of tobacco users screened self-reported current anxiety and/or depression.
Available data suggests the rate of lifetime anxiety and major depression in the general Canadian population is $12 \%$ and $8 \%$, respectively. ${ }^{26}$ Vermani and colleagues ${ }^{27}$ found rates of major depression $(27.2 \%)$ and generalized anxiety disorder $(31.2 \%)$ to be higher among patients in Canadian primary care practice settings than in the general population. The co-occurrence of smoking with anxiety, depression and other mental health disorders is well known, with rates of nicotine dependence 3-6 times higher in such individuals. ${ }^{28-30}$ Consistent with previous research, female tobacco users reported they were currently suffering from anxiety and depression significantly more frequently than males $(47.7 \%$ v. $36.3 \%) .{ }^{31,32}$ Heavier rates of smoking and higher levels of nicotine addiction were also reported among tobacco users who reported anxiety or depression compared with those without mental health illness. The rates of anxiety and depression observed is particularly relevant given

Table 2: Profile of tobacco users by presence of self-reported anxiety or depression*

\begin{tabular}{|c|c|c|}
\hline \multirow[b]{2}{*}{ Characteristic } & \multicolumn{2}{|c|}{ Self-reported anxiety or depression, \%† } \\
\hline & $\begin{array}{l}\text { Reported } \\
n=2379\end{array}$ & $\begin{array}{c}\text { Not reported } \\
n=2787\end{array}$ \\
\hline Age, mean $(95 \% \mathrm{Cl})$, yr & $46.2(45.6-46.7)$ & $48.4(47.9-49.0)$ \\
\hline \multicolumn{3}{|l|}{ Sex } \\
\hline Male & 36.3 & 63.7 \\
\hline Female & 47.7 & 52.3 \\
\hline Years of formal education, mean $(95 \% \mathrm{Cl})$ & $13.3(13.2-13.4)$ & $13.3(13.2-13.4)$ \\
\hline \multicolumn{3}{|l|}{ Smoking-related illness, \% } \\
\hline Heart disease, heart attack, heart failure, stroke & 11.6 & 10.3 \\
\hline Diabetes & 13.8 & 12.4 \\
\hline Cancer & 4.0 & 3.7 \\
\hline COPD & 11.7 & 5.9 \\
\hline Cigarettes per day, mean $(95 \% \mathrm{Cl})$ & $17.5(17.1-17.9)$ & $15.8(15.5-16.2)$ \\
\hline No. of years smoking, mean $(95 \% \mathrm{Cl})$ & $26.5(25.9-27.1)$ & $28.3(27.8-28.9)$ \\
\hline \multicolumn{3}{|l|}{ Time (min) to first cigarette in the morning } \\
\hline$>60$ & 16.2 & 22.7 \\
\hline $31-60$ & 17.6 & 20.4 \\
\hline $6-30$ & 34.4 & 35.6 \\
\hline$\leq 5$ & 31.8 & 21.3 \\
\hline \multicolumn{3}{|l|}{ Readiness to quit§ } \\
\hline Ready in next $30 \mathrm{~d}$ & 29.8 & 30.3 \\
\hline Ready in next 6 mo & 41.7 & 40.6 \\
\hline Not ready & 28.5 & 29.2 \\
\hline Cessation self-efficacy, mean score $(95 \% \mathrm{CI}) \uparrow$ & $4.9(4.7-5.0)$ & $5.3(5.2-5.4)$ \\
\hline \multicolumn{3}{|c|}{$\begin{array}{l}\text { Note: } \mathrm{Cl}=\text { confidence interval, } \mathrm{COPD}=\text { chronic obstructive pulmonary disease. } \\
\text { "Self-reported presence of current anxiety or depression: "Do you have any of the following conditions?: anxiety or depression." } \\
\text { †Unless stated otherwise. } \\
\text { †In response to the question, "How soon after you wake up do you smoke your first cigarette?" } \\
\text { §ln response to the question, "Which of the following best describes your feelings about quitting smoking right now?" } \\
\text { १ln response to the question, "On a scale of } 0 \text { to } 10 \text { how confident are you that you would be able to quit smoking at this time? }(0=\text { not at all } \\
\text { confident, } 10=\text { extremely confident)." }\end{array}$} \\
\hline
\end{tabular}




\section{OPEN}

Research

that poorer cessation outcomes have been documented among individuals who report anxiety or depression. ${ }^{33} \mathrm{We}$ did not find, however, that the presence of anxiety or depression predicted readiness to quit smoking, which is consistent with previous reports by Hall and colleagues. ${ }^{34,35}$ About a third of tobacco users reported an interest in quitting in the next 30 days. Patients not ready to quit reported lower rates of confidence with quitting than those ready to quit. Increasing patient confidence in their ability to quit is an important goal for patients not ready to quit in the next 30 days. An association was also documented between readiness to quit and years of smoking, which suggests individuals who have been smoking less than 5 years are less likely to be ready to quit in the immediate future.

\section{Limitations}

The following limitations should be considered when interpreting our findings. First, the study was conducted in a sample of primary care practices in Ontario, Canada, and may not be generalizable to other primary care practices. We had a greater rate of nonparticipation from urban primary care clinics. Clinics in urban centres were more likely to identify competing demands as the reason for nonparticipation. A total of $56.9 \%$ of eligible tobacco users participated in the survey. Unfortunately, 528 patients who agreed to participate did not return their survey. Future studies should examine methods of reducing barriers to participation to increase representativeness. Additionally, self-report was used for data collection and may be subject to respondent error. The use of standardized

Table 3: Final multilevel logistic regression model* examining variables associated with readiness to quit in next 30 days $\dagger$

\begin{tabular}{|c|c|}
\hline Variable & OR $(95 \% \mathrm{Cl})$ \\
\hline \multicolumn{2}{|l|}{ Sex } \\
\hline Male & 1.00 \\
\hline Female & $0.85(0.74-0.97)$ \\
\hline \multicolumn{2}{|l|}{ COPD } \\
\hline No & 1.00 \\
\hline Yes & $1.76(1.4-2.2)$ \\
\hline \multicolumn{2}{|c|}{ No. of years smoking } \\
\hline$<5$ & 1.00 \\
\hline $5-15$ & $1.54(1.19-2.11)$ \\
\hline$>15$ & $1.12(0.93-1.36)$ \\
\hline \multicolumn{2}{|c|}{ Cessation self-efficacy scoreł } \\
\hline$<7$ & 1.00 \\
\hline$\geq 7$ & $3.58(3.13-4.10)$ \\
\hline \multicolumn{2}{|c|}{$\begin{array}{l}\text { Note: } \mathrm{Cl}=\text { confidence interval, } \mathrm{COPD}=\text { chronic obstructive pulmonary disease, } \\
\text { OR = odds ratio. } \\
\text { "Model adjusted for clinic-level clustering effects. } \\
\text { †"Which of the following best describes your feelings about quitting smoking right } \\
\text { now?" Response: "I would like to quit in the next } 30 \text { days." } \\
\text { fln response to the question, "On a scale of } 0 \text { to } 10 \text { how confident are you that } \\
\text { you would be able to quit smoking at this time? }(0=\text { not at all confident, } 10= \\
\text { extremely confident)." }\end{array}$} \\
\hline
\end{tabular}

assessment for screening of anxiety and depression would be valuable in future studies to validate our findings.

\section{Conclusion}

This study provides a profile of tobacco users identified in a large sample of primary care practices in Ontario. Tobacco users reported high rates of nicotine dependence and anxiety and/or depression, but also high rates of readiness to quit. Our findings may have important implications for informing future research and practice, and increasing both the uptake and outcomes of tobacco treatment interventions delivered in primary care settings. Given the high rates of anxiety and depression among tobacco users in primary care settings, integrated interventions in which both nicotine addiction and anxiety/depression are addressed is an important focus for future research.

\section{Table 4: Final multilevel logistic regression model* examining variables associated with the presence of self-reported anxiety or depression}

Variable OR $(95 \% \mathrm{Cl}) \dagger$

Age, yr

$\leq 24$ 1.00

$25-44$ $1.53(1.10-2.14)$

$45-64$ $2.24(1.79-2.80)$

$\geq 65$ $1.70(1.39-2.09)$

Sex

Male 1.00

Female $1.66(1.47-1.88)$ COPD

No 1.00

Yes $2.16(1.73-2.67)$

No. of years smoking

$<5$

$5-15$ 1.00

$>15$

$1.68(1.24-2.27)$

\section{Time ( $\mathrm{min})$ to first cigarette in the} morning¥

\begin{tabular}{|cc|}
\hline$>60$ & 1.00 \\
\hline $31-60$ & $1.21(0.99-1.47)$ \\
\hline $6-30$ & $1.37(1.15-1.62)$ \\
\hline$\leq 5$ & $2.00(1.66-2.40)$ \\
\hline Cessation self-efficacy§ & 1.00 \\
\hline$<7$ & $0.78(0.69-0.90)$ \\
\hline$\geq 7$ & \\
\hline
\end{tabular}

Note: $\mathrm{Cl}$ = confidence interval, $\mathrm{COPD}=$ chronic obstructive pulmonary disease, $\mathrm{OR}=$ odds ratio

*Model adjusted for clinic-level clustering effects.

$\dagger 1=$ self-reported anxiety or depression $(n=2379) ; 0=$ did not self-report anxiety or depression $(n=2787$ ).

‡"How soon after you wake up do you smoke your first cigarette?" $\S$ "On a scale of 0 to 10 how confident are you that you would be able to quit smoking at this time? ( $0=$ not at all confident, $10=$ extremely confident)." 


\section{References}

1. WHO report on the global tobacco epidemic, 2008: the MPOWER package. Geneva: World Health Organization; 2008. Available: www.who.int/tobacco /mpower/mpower_report_full_2008.pdf (accessed 2015 July 1).

2. McIvor A, Kayser J, Assaad JM, et al. Best practices for smoking cessation interventions in primary care. Can Respir 7 2009;16:129-34.

3. Guttman A, Schult SE, Jaakkimainen L. Ambulatory physician care for adults. In: Primary care in Ontario: ICES atlas. Toronto: Institute for Clinical Evaluative Sciences; 2006.

4. Reid J, Hammond D, Burkhalter R, et al. Tobacco use in Canada: patterns and trends, 2012 edition. Waterloo (ON): Propel Centre for Population Health Impact; 2012.

5. Zwar NA, Richmond RL. Role of the general practitioner in smoking cessation. Drug Alcohol Rev 2006;25:21-6.

6. Smoking cessation during previous year among adults - United States, 1990 and 1991. MMWR Morb Mortal Wkly Rep 1993;42:504-7.

7. Vardavas CI, Symvoulakis EK, Lionis C. Dealing with tobacco use and dependence within primary health care: time for action. Tob Induc Dis 2013;11:6.

8. Papadakis S, Gharib M, Hambleton J, et al. Delivering evidence-based smoking cessation treatment in primary care practice: experience of Ontario family health teams. Can Fam Physician 2014;60:e362-71.

9. Longo DR, Stone TT, Phillips RL, et al. Characteristics of smoking cessation guideline use by primary care physicians. Mo Med 2006;103:180-4.

10. Tong EK, Strouse R, Hall J, et al. National survey of US health professionals' smoking prevalence, cessation practices, and beliefs. Nicotine Tob Res 2010; 12:724-33

11. Vogt F, Hall S, Hankins M, et al. Evaluating three theory-based interventions to increase physicians' recommendations of smoking cessation services. Health Psychol 2009;28:174-82.

12. Vogt F, Hall S, Marteau TM. General practitioners' beliefs about effectiveness and intentions to recommend smoking cessation services: qualitative and quantitative studies. BMC Fam Pract 2007;8:39.

13. Perez-Rios M, Santiago-Perez MI, Alonso B, et al. Fagerstrom test for nicotine dependence vs heavy smoking index in a general population survey. $B M C$ Public Health 2009;9:493.

14. Velicer WF, Fava JL, Prochaska JO, et al. Distribution of smokers by stage in three representative samples. Prev Med 1995;24:401-11.

15. Brandon TH, Herzog TA, Juliano LM, et al. Pretreatment task persistence predicts smoking cessation outcome. 7 Abnorm Psychol 2003;112:448-56.

16. Bandura A. Guide for constructing self-efficacy scales. In: Self-efficacy beliefs of adolescents. Information Age Publishing; 2006: 307-33.

17. Bandura A. Self-efficacy: the exercise of control. New York: Freeman; 1997.

18. Gwaltney CJ, Metrik J, Kahler CW, et al. Self-efficacy and smoking cessation: a meta-analysis. Psychol Addict Behav 2009;23:56-66.

19. McIvor A. Tobacco control and nicotine addiction in Canada: current trends, management and challenges. Can Respir 7 2009;16:21-6.

20. Corsi DJ, Lear SA, Chow CK, et al. Socioeconomic and geographic patterning of smoking behaviour in Canada: a cross-sectional multilevel analysis. PLOS ONE 2013;8:e57646.

21. Smoke-free Ontario strategy monitoring report. Toronto: Ontario Tobacco Research Unit; 2014.

22. Burgess DJ, Fu SS, Noorbaloochi S, et al. Employment, gender, and smoking cessation outcomes in low-income smokers using nicotine replacement therapy. Nicotine Tob Res 2009;11:1439-47.

23. Hyland A, Borland R, Li Q, et al. Individual-level predictors of cessation behaviours among participants in the international tobacco control (ITC) four country survey. Tob Control 2006;15(Suppl 3):iii83-94.
24. Breslau N, Johnson EO. Predicting smoking cessation and major depression in nicotine-dependent smokers. Am 7 Public Health 2000;90:1122-7.

25. Piper ME, McCarthy DE, Baker TB. Assessing tobacco dependence: a guide to measure evaluation and selection. Nicotine Tob Res 2006;8:339-51.

26. Smetanin P, Stiff D, Briante C, et al. The life and economic impact of major mental illnesses in Canada: 2011 to 2041. Calgary: Mental Health Commission of Canada; 2011.

27. Vermani M, Marcus M, Katzman MA. Rates of detection of mood and anxiety disorders in primary care: a descriptive, cross-sectional study. Prim Care Companion CNS Disord 2011;13: 10.4088/PCC.10m01013.

28. Grant BF, Hasin DS, Chou SP, et al. Nicotine dependence and psychiatric disorders in the United States: results from the national epidemiologic survey on alcohol and related conditions. Arch Gen Psychiatry 2004;61:1107-15.

29. Glassman AH, Helzer JE, Covey LS, et al. Smoking, smoking cessation, and major depression. 7AMA 1990;264:1546-9.

30. Lasser K, Boyd JW, Woolhandler S, et al. Smoking and mental illness: a population-based prevalence study. 7AMA 2000;284:2606-10.

31. Weissman MM, Bland R, Joyce PR, et al. Sex differences in rates of depression: cross-national perspectives. 7 Affect Disord 1993;29:77-84.

32. Gater R, Tansella M, Korten A, et al. Sex differences in the prevalence and detection of depressive and anxiety disorders in general health care settings: report from the world health organization collaborative study on psychological problems in general health care. Arch Gen Psychiatry 1998;55:405-13.

33. Cook BL, Wayne GF, Kafali EN, et al. Trends in smoking among adults with mental illness and association between mental health treatment and smoking cessation. FAMA 2014;311:172-82.

34. Hall SM, Prochaska JJ. Treatment of smokers with co-occurring disorders: emphasis on integration in mental health and addiction treatment settings. Annu Rev Clin Psychol 2009;5:409-31.

35. Hall SM, Tsoh JY, Prochaska JJ, et al. Treatment for cigarette smoking among depressed mental health outpatients: a randomized clinical trial. Am 7 Public Health 2006;96:1808-14.

Affiliation: Division of Prevention and Rehabilitation, University of Ottawa Heart Institute, Ottawa, Ont.

Contributors: All of the authors contributed to the design of the study. Sophia Papadakis drafted the manuscript, which all of the authors reviewed. All of the authors gave final approval of the version to be published and agreed to act as guarantors of the work.

Funding: This study was supported by an educational grant from the Heart and Stroke Foundation of Ontario, Pfizer Global and the Canadian Tobacco Control Research Initiative. Sophia Papadakis was supported with doctoral fellowships from the Canadian Institutes of Health Research (CIHR) Strategic Training Program in Tobacco Research and the CIHR Training Program in Population Intervention for Chronic Disease Prevention.

Acknowledgement: The authors thank the staff of all of the participating primary care practices for their contributions to this study.

Supplemental information: For reviewer comments and the original submission of this manuscript, please see www.cmajopen.ca/content/4/1/ E41/suppl/DC1. 